\title{
Graphite Oxide: An Interesting Candidate for Aqueous
}

\section{Supercapacitors}

\author{
Belén Lobato $^{\mathrm{a}}$, Rune Wendelbo ${ }^{\mathrm{b}}$, Violeta Barranco ${ }^{\mathrm{c}}$, Teresa A. Centeno ${ }^{\mathrm{a}}$ * \\ ${ }^{a}$ Instituto Nacional del Carbón-CSIC, Apartado 73, 33080 Oviedo, Spain \\ ${ }^{\mathrm{b}}$ Abalonyx AS, Forskningsveien 1, 0373 Oslo, Norway.

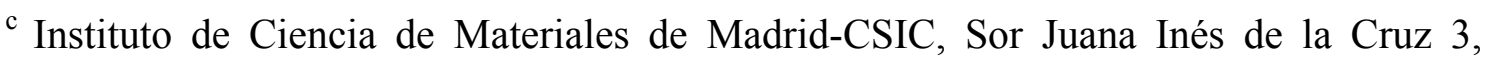 \\ Cantoblanco, 28049 Madrid, Spain.
}

\section{Highlights}

- The potential of graphite oxide as supercapacitor electrode is explored

- Graphite oxide reaches $177 \mathrm{~F} / \mathrm{cm}^{3}$ in $\mathrm{H}_{2} \mathrm{SO}_{4}$ and $59 \mathrm{~F} / \mathrm{cm}^{3}$ in $\mathrm{TEABF}_{4} /$ acetonitrile

- It surpasses the energy stored by graphene nanoplatelets in aqueous $\mathrm{H}_{2} \mathrm{SO}_{4}$

- It largely exceeds the power capability of an activated carbon in aqueous $\mathrm{H}_{2} \mathrm{SO}_{4}$

- Standard gas adsorption does not provide the active surface in the supercapacitor

\footnotetext{
* Corresponding author: Tel. (+34) 985119090.

E-mail address: teresa@incar.csic.es (T.A. Centeno)
} 


\section{Graphical Abstract}
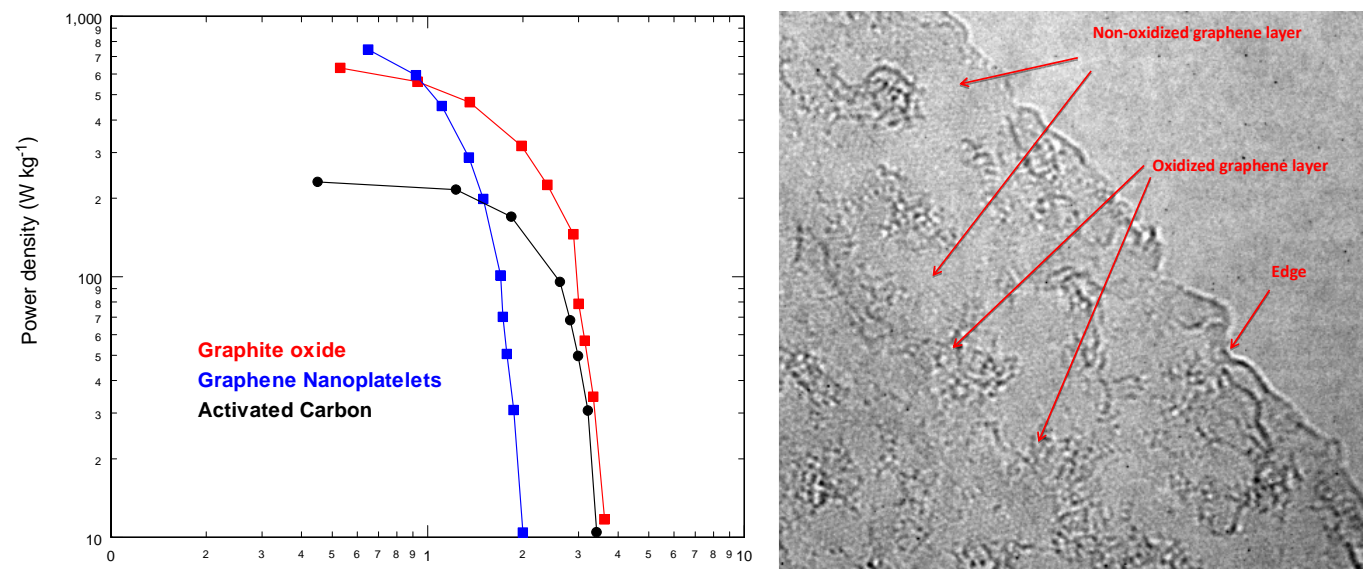

Energy density $\left(\mathrm{Wh} \mathrm{kg}^{-1}\right)$ 


\section{ABSTRACT}

A graphite oxide, obtained on a large scale at low cost as an intermediate in the graphene production, achieves specific capacitances $\left(159 \mathrm{Fg}^{-1}\right.$ in $\mathrm{H}_{2} \mathrm{SO}_{4}$ and $82 \mathrm{Fg}^{-1}$ in $\left(\mathrm{C}_{2} \mathrm{H}_{5}\right)_{4} \mathrm{NBF}_{4}$ in acetonitrile) that compete with those of activated carbons and largely surpass the values obtained with graphene nanoplatelets. More promising, the high electrode density leads to volumetric capacitances of 177 and $59 \mathrm{~F} \mathrm{~cm}^{-3}$ in the aqueous and the organic electrolytes, respectively, which are above most data reported for carbons. In the aqueous electrolyte, the graphite oxide stands out on energy density when compared to graphene nanoplatelets and on power capability if compared to an activated carbon commercialized for supercapacitors, whereas in the organic electrolyte, the limited interlayer spacing restricts the mobility of the larger ions into the expanded graphitic structure. This study also illustrates that the specific surface of carbons measured by standard gas adsorption may not be a relevant parameter as it does not always match the electrochemically active area involved in the energy storage.

Keywords: Graphite oxide, Surface area, Electrochemical double-layer, Supercapacitor

\section{Introduction}

Supercapacitors (SC) are under an increasing demand as alternative energy storage devices. Their high rate capability, pulse power supply, long cycle life and low maintenance cost make them highly attractive for powering electric vehicles, portable electronic devices, uninterruptable power supplies, etc. [1]

The electrochemical double layer capacitor (EDLC) is a type of supercapacitor in which the energy is physically stored by means of ion adsorption at the electrode/electrolyte interface [2]. A wide variety of carbons (activated carbons, carbon nanotubes, templated carbons, carbide-derived carbons, carbon gels, carbon blacks, glassy carbons, etc.) have 
been extensively investigated as electrodes in EDLC [3-10]. The number of candidates has increased with the recently discovered graphene, since its large theoretical surface area and high electrical conductivity result key features for application in SC [11-14].

In spite of the potential of graphene, it still needs to compete with activated carbons in terms of cost/performance $[11,12,15]$ to be used in practice. In this context, up-to-now the most promising approach to obtain graphene for SC involves the chemical oxidation of graphite followed by an exfoliation process to produce graphene oxide and, finally, a controllable reduction to obtain reduced graphene oxide [11-14]. As lower-cost materials for supercapacitors are a priority, the intermediate graphene oxide will have an advantage over reduced graphene oxide. It has been reported that graphene oxide itself may be promising in EDLC electrodes $[16,17]$ but its application appears to be limited by its low conductivity $[11,12,14]$.

Currently, graphene oxide has not been commercially available in large quantities, normally selling in gram quantities, partly due to the lack of a sustainable production process. However, Abalonyx AS, a Norwegian technology start-up company, has recently developed an improved method for the production of graphene oxide, based on a modified Hummers procedure $[18,19]$, that will now be mass produced. Nitrate is not used in order to avoid noxious fumes, resulting in a more environmentally friendly process now being scaled to tons/year capacity.

Herein, we report that graphite oxide, generated on a large scale at low cost in the early stages of graphene oxide preparation may become competitive for electrodes in aqueous supercapacitors. The systematic comparison of its electrochemical performance with an activated carbon available on the market for SC and commercial graphene nanoplatelets provides reliable information on the relative potential of the graphite oxide for energy storage devices. 


\section{Experimental Section}

\subsection{Material preparation}

Graphite oxide S43 was prepared on large scale by a modified Hummers method [16, 18] using 100 g Nanocon-1 graphite (NNC Corporation, Japan) as raw material resulting in about $160 \mathrm{~g}$ graphite oxide. After oxidation, the material was washed twice with $5 \% \mathrm{HCl}$ and once with $1 \% \mathrm{HCl}$ and finally centrifuged, resulting in a thick aqueous paste with about $32 \mathrm{wt} \%$ graphite oxide. The material was spread on a plastic sheet and air-dried over night. As a result dry flakes of graphite oxide were obtained.

\subsection{Material characterization}

A variety of techniques was used to monitor the chemical and structural changes occurring in the different materials. Experimental details are described in the Supporting Information (SI).

The chemical characterization of the sample used (batch S-43) was carried out by elemental microanalysis and by X-ray photoelectron spectroscopy (XPS). It was further studied by Thermal Programmed Desorption (TPD) experiments from room temperature to $1000^{\circ} \mathrm{C}$.

The morphology of the samples was examined by Scanning Electron Microscopy whereas the structural characterization involved X-Ray Diffraction and Raman Spectroscopy.

The textural features were estimated from physisorption isotherms of $\mathrm{N}_{2}$ at $77 \mathrm{~K}$ and $\mathrm{CO}_{2}$ at $273 \mathrm{~K}$. The density of the sample was determined by He picnometry. 
The electrochemical performance was tested in a sandwich-type capacitor set up with two carbon pellets separated by glassy fibrous paper $(300 \mu \mathrm{m}$ thick $)$ and placed in a Swagelok cell. The dried S43 flakes were mixed with polytetrafluoroethylene to form electrodes consisting of 95 wt.\% active material and 5 wt.\% binder. The electrode was rolled to a thickness of $\sim 140 \mu \mathrm{m}$, punched into a $8 \mathrm{~mm}$ diameter and dried in an oven at $100^{\circ} \mathrm{C}$ for $24 \mathrm{~h}$. Due to the poor performance, the carbon black Super-P (MMM Carbon) was further added to the composite electrode. The electrolytes were $2 \mathrm{M} \mathrm{H}_{2} \mathrm{SO}_{4}$ aqueous solution and $1 \mathrm{M}\left(\mathrm{C}_{2} \mathrm{H}_{5}\right)_{4} \mathrm{NBF}_{4}$ in acetonitrile $\left(\mathrm{TEABF}_{4} / \mathrm{AN}\right)$. The capacitance was determined by galvanostatic charge-discharge cycles (Autolab-Ecochimie PGSTAT 30) at different current densities, from 1 to $100 \mathrm{~mA} \mathrm{~cm}^{-2}$, and cyclic voltammetries at scan rates ranging between 1 and $50 \mathrm{mVs}^{-1}$. The cell voltage ranged from 0 to $0.8 \mathrm{~V}$ for aqueous medium and between 0 and $2 \mathrm{~V}$ for the organic electrolyte. The gravimetric capacitance $\left(\mathrm{F} \mathrm{g} \mathrm{g}^{-1}\right)$ given in the present study is relative to the graphite oxide mass in a single electrode made of $90 \%$ wt. of S43, $5 \%$ wt. of PTFE and $5 \%$ wt. of Super-P. The experimental values reported correspond to those obtained after 10 charge-discharge cycles for each current intensity.

Electrochemical impedance spectroscopy (EIS) measurements were performed using a by sinusoidal signal of $\pm 15 \mathrm{mV}$ from $210^{-4} \mathrm{~Hz}$ to $60 \mathrm{kHz}$ in a PGSTAT 30 (Autolab B.V., Metrohm) potentiostat equipped with a FRA32M module.

The electrochemical performance of the graphite oxide was systematically compared with two carbons available on the market: i) the activated carbon Picactif SC (Pica, USA) and ii) graphene nanoplatelets C-750 (XG Sciences, USA) (see Supporting Information). The three samples were tested under the same experimental conditions.

\section{Results and Discussion}


The procedure developed by Abalonyx results in an extensive oxidation as indicated by the high increase in the oxygen percentage from 0.3 wt. $\%$ of the raw graphite to 39.2 wt.\% for the graphite oxide material (labeled as S43). TPD experiments (Figure 1) reveal the presence of labile oxygen-containing functionalities which start releasing even below $100^{\circ} \mathrm{C}$.

There is an abrupt generation of $\mathrm{CO}$ and $\mathrm{CO}_{2}$ in a very narrow range at around a temperature as low as $127^{\circ} \mathrm{C}$ which results in blasting (Figure 1). Such behavior indicates a high concentration of oxygen functional groups intercalated into the graphene sheets which diminishes the Van der Waals interactions [20, 21]. Moreover, there is a continuous and smooth weight loss between 350 and $1000^{\circ} \mathrm{C}$ which corresponds mainly to the release of more stable functionalities desorbing as $\mathrm{CO}$. The high concentration of oxygen functional groups is also confirmed by $\mathrm{C} / \mathrm{O}$ ratio of 2.6, estimated by XPS. The surface oxygen is distributed in $23.2 \%$ of C-O (epoxy, hydroxyl) bonds, $14.2 \%$ of $\mathrm{C}=\mathrm{O}$ functionalities and $16.8 \%$ of $\mathrm{OH}-\mathrm{C}=\mathrm{O}$ carboxyl type-groups.

SEM images illustrate that S43 is composed of flakes with a layered structure (Figure 2a, see also Figure S1). The analysis by HRTEM (Figure 2b, see also Figure S2) reveals the presence of both graphene layers and oxidized regions with surface functional groups.

As reported by XRD profiles (Figure 3a), the oxidation based on Hummers'method induces a significant expansion in the graphite structure [21]. The intense (001) peak at $13.64^{\circ}$ observed for S43 derives from the incorporation of water and oxygenatedfunctionalities on the carbon sheets which leads to the widening of the interlayer spacing from the typical $0.34 \mathrm{~nm}$ to $\sim 0.65 \mathrm{~nm}$ on average. 
In the Raman spectrum, a wide D-band typical for $\mathrm{sp}^{3}$ hybridation becomes prominent and the relative intensity of $\mathrm{D}$ to $\mathrm{G}$ band, $\mathrm{I}_{\mathrm{D}} / \mathrm{I}_{\mathrm{G}}$, is around 0.9 (Figure $3 \mathrm{~b}$ ). This indicates the reduction of the in-plane $\mathrm{sp}^{2}$ domains induced by the introduction of defective levels (edges, atomic vacancies, functionalities) and disorder [22]. XPS reports $22.2 \%$ of C-C in aromatic rings.

The electrochemical performance of the graphite oxide was tested in a sandwich-type capacitor set up with two electrodes separated by glassy fibrous paper. In a first attempt, the electrodes were formed by $95 \%$ wt. of S43 and $5 \%$ wt. of PTFE as binder. The collapsed cyclic voltammogram at $1 \mathrm{mV} \mathrm{s}^{-1}$ in $\mathrm{H}_{2} \mathrm{SO}_{4}$ (Figure 4, left) reveals an extremely low electrical conductivity which prevents electrochemical energy storage. As illustrated by Figure 4, this shortcoming can be overcome by the addition of a carbon black to the composite electrode.

The steep current change at the switching potentials (Figure 4, right) reflects quick charge propagation in the electrodes made of $90 \% \mathrm{wt}$. of S43, $5 \% \mathrm{wt}$. of PTFE and 5 \%wt. of Super-P, the clear rectangular-shaped CV curve confirming the suitability of the graphite oxide for electrochemical capacitors.

An outstanding performance of the graphite oxide S43 is suggested by Figure 5 where the dependence of the limiting capacitance (estimated at $1 \mathrm{~mA} \mathrm{~cm}^{-2}$ ) with the total surface area for a variety of activated carbons is shown. The analysis of $\mathrm{N}_{2}$ adsorption isotherm $(77 \mathrm{~K})$ on $\mathrm{S} 43$ powder leads to a specific surface area $\mathrm{S}_{\mathrm{BET}}$ of only $15 \mathrm{~m}^{2} \mathrm{~g}^{-1}(8$ $\mathrm{m}^{2} \mathrm{~g}^{-1}$ in the electrode) whereas specific capacitances as high as $159 \mathrm{~F} \mathrm{~g}^{-1}$ in the aqueous electrolyte and $82 \mathrm{~F} \mathrm{~g}^{-1}$ in the organic medium are achieved. These values compare with those of activated carbons and other porous carbons with specific surface area around 900-1200 $\mathrm{m}^{2} \mathrm{~g}^{-1}$ [23-31] and largely surpass those achieved by the graphene nanoplatelets. 
It can be assumed that, in the aqueous electrolyte, the abundant oxygen-containing groups attached to the S43 surface act as redox sites and provide a significant pseudocapacitance, leading to an enhancement of the overall capacitance. However, the extremely high values cannot be explained based solely on huge pseudocapacitance contributions. Moreover, in the case of the organic electrolyte the pseudocapacitive processes do not apply significantly [24,29-31] and the capacitance is mainly due to the extent of the surface accessible to the ions.

The anomalous high surface related-capacitance in both electrolytes may suggest that the expanded graphitic structure induces a capacitance enhancement. The characterization of $\mathrm{S} 43$ by $\mathrm{CO}_{2}$ adsorption at $273 \mathrm{~K}$ provides some further insights. The analysis of the $\mathrm{CO}_{2}$ isotherm by the Dubinin-Radushkevich equation [32] reports a micropore volume of $0.09 \mathrm{~cm}^{3} \mathrm{~g}^{-1}$ with an average micropore size of $1.06 \mathrm{~nm}$ and a surface area of $178 \mathrm{~m}^{2} \mathrm{~g}^{-1}$ (much higher than the $15 \mathrm{~m}^{2} \mathrm{~g}^{-1}$ from $\mathrm{N}_{2}$ adsorption). The characteristic curve [32,33] in Figure 6 reflects the significant difference in the adsorption of $\mathrm{N}_{2}$ and $\mathrm{CO}_{2}$ by the graphite oxide.

As previously reported [33], the low $\mathrm{N}_{2}$ adsorption capacity does not indicate the absence of porosity but a hindered access. Due to the low adsorption temperature (77 $\mathrm{K})$, the filling of narrow cavities is a very slow process, and the equilibrium is not achieved under the standard operation times. By contrast, $\mathrm{CO}_{2}$ is adsorbed more quickly as the higher adsorption temperature $(273 \mathrm{~K})$ allows avoiding diffusional problems.

Even using the surface estimated by $\mathrm{CO}_{2}$, the present carbon exhibits a much higher capacitance per specific surface area (in $\mathrm{F} \mathrm{m}^{-2}$ ) than other porous carbons [29,34]. This suggest that the specific surface area determined by standard gas adsorption (i.e. $\mathrm{N}_{2}$ and $\mathrm{CO}_{2}$ as adsorbates) may be misleading in the present case as it does not match the electrochemically active surface of the carbon in the SC. As previously reported [35- 
37], the high gravimetric capacitance of S43 would result from intercalation of the electrolytes into the expanded graphene sheets.

Taking into account a contribution from the double layer in the organic electrolyte of around $0.095 \mathrm{~F} \mathrm{~m}^{-2}$ (obtained by a systematic study of a large variety of carbon materials) $[29,34]$, one obtains that the surface of S43 participating in energy storage would be around $860 \mathrm{~m}^{2} \mathrm{~g}^{-1}$.

This value and the surface capacitance of $0.105 \mathrm{~F} \mathrm{~m}^{-2}[29,34]$ found for carbons in the aqueous electrolyte allows estimating a pseudocapacitance of $69 \mathrm{Fg}^{-1}$ which corresponds to $\sim 44 \%$ of the overall capacitance of the graphite oxide in $2 \mathrm{M} \mathrm{H}_{2} \mathrm{SO}_{4}$.

This pseudocapacitive contribution appears to display a good reversibility. In fact, after very stressful electrochemical measurements by cyclic voltammetry, galvanostatic cycling and electrochemical impedance spectroscopy, the original performance was further cross-checked by repeating some tests and remained unchanged.

From an industrial point of view, it is important to note that the high true density of the graphite oxide $\left(1.90 \mathrm{~g} \mathrm{~cm}^{-3}\right)$ as well as its good packing at electrode $\left(1.24 \mathrm{~g} \mathrm{~cm}^{-3}\right)$ lead to volumetric capacitances of $177 \mathrm{~F} \mathrm{~cm}^{-3}$ in $\mathrm{H}_{2} \mathrm{SO}_{4}$ and $59 \mathrm{~F} \mathrm{~cm}^{-3}$ in $\mathrm{TEABF}_{4} / \mathrm{AN}$, which are above most values reported for carbon-based electrodes [38]. This feature is highly relevant for the design of compact devices.

As shown in Figure 7, the rate capability of the graphite oxide in the aqueous $\mathrm{H}_{2} \mathrm{SO}_{4}$ electrolyte is very similar to that of the activated carbon Picactif and the capacitance at $70 \mathrm{mAcm}^{-2}$ maintains about $60 \%$ of the limiting value at $1 \mathrm{~mA} \mathrm{~cm}$. Although the capacitance decaying rate for S43 is more marked than that observed for the graphene nanoplatelets, the value at $100 \mathrm{~mA} \mathrm{~cm}^{-2}$ still remains $26 \%$ higher than that of the graphene nanoplatelets. 
The Nyquist plot of the cell (Figure S3, Supporting Information) provides insights on the response with the operating frequency. A magnification of the high frequency region (Figure 8) confirms that the graphite oxide and Picactif display a similar behavior in $\mathrm{H}_{2} \mathrm{SO}_{4}$ although the typical $45^{\circ}$ segment due to the resistance of ions diffusion into the bulk of S43 is somewhat larger. In the case of the graphene nanoplatelets, there is a short transition between the semicircle and the vertical capacitive behavior indicating that the diffusional contribution is much less relevant and the ESR is significantly lower.

The constant time $\tau$ (i.e. the minimum time the cell needs to be charged or discharged) outlined in Figure 8 (inset) shows that the narrow spacing in S43 does not affect significantly the charge/discharge process in the aqueous medium and $\tau$ is $7.9 \mathrm{~s}$ for the S43 against $10 \mathrm{~s}$ for Picactif. The higher value for Picactif may be related to the larger extension of the surface area accessible to the electrolyte rather than to limitations from the pore width.

Ragone-type plot relating energy storage capacity (energy density) to average power density (both obtained from the galvanostatic cycles) summarizes the potential of the graphite oxide for aqueous supercapacitor. Figure 9 provides quite reliable information as far as all samples were tested under the same experimental conditions at lab-scale. As the supercapacitor performance also depends on the experimental device, the values are not relevant but the profiles themselves.

The comparison with the devices based on the other two carbons reports that S43 successfully competes with the high-surface activated carbon in terms of energy-density whereas it provides a similar power to that of graphene nanoplatelets.

In the organic electrolyte, the performance of S43 is far below that of the commercial carbons. The drop in the specific capacitance with the current density (Figure 7) reflects 
the difficulties of the relatively large $\mathrm{TEA}^{+}$ion $(0.68 \mathrm{~nm})$ to access and to move in the interlayer spacing $(\sim 0.65 \mathrm{~nm}$ as determined by XRD) and the supercapacitor suffers from slow charge-discharge rate.

The Nyquist plot (Figure 8) shows that the vertical capacitive behavior in the low frequency region is deflected due to diffusional constrictions. Moreover, the time constant peak is formed by two contributions, indicating the presence of regions with significant differences in the accessibility. Further developments of the oxidation process are in due course to achieve larger spacing between the carbon sheets which would definitely enhance the performance of the organic supercapacitor.

\section{Conclusions}

It is shown that graphite oxidation may be an interesting alternative pathway to obtain carbons for supercapacitors.

The low electrical conductivity of the graphite oxide can be overcome by the addition of a carbon black (5 wt.\%) to the composite electrode. In this way, a graphite oxide obtained at large scale achieves a specific capacitance as high as $159 \mathrm{~F} \mathrm{~g}^{-1}$ in the aqueous electrolyte $\mathrm{H}_{2} \mathrm{SO}_{4}$ and $82 \mathrm{~F} \mathrm{~g}^{-1}$ in the organic medium $\left(\mathrm{C}_{2} \mathrm{H}_{5}\right)_{4} \mathrm{NBF}_{4}$ in acetonitrile. These values compare with those of activated carbons and other porous carbons with specific surface area around $1000 \mathrm{~m}^{2} \mathrm{~g}^{-1}$ and largely surpass that found for graphene nanoplatelets. Besides, the graphite oxide shows much higher volumetric capacitance than the majority of carbons which is a key factor for the development of small devices.

The performance at high current density of the graphite oxide is very promising in the aqueous electrolyte since it stands out on energy density when compared to commercial 
graphene nanoplatelets and power capability when compared to the activated carbon Picactif SC.

The difficulties of the relatively large organic cation $\mathrm{TEA}^{+}$to move in an interlayer space of similar dimensions derives in a slow charge-discharge rate and in a drop in the power release. Further developments of the oxidation process are in due course to achieve a nanoengineered spacing to facilitate the mobility of the larger ions into the expanded graphitic structure. This would definitely enhance the performance of the graphite oxide in the organic supercapacitor.

This study also illustrates that the popular approach based on the specific surface area to assess the potential of carbons in SC cannot be used in a straightforward manner. For certain carbons, the surface measured by standard gas adsorption (i.e. $\mathrm{N}_{2}$ and $\mathrm{CO}_{2}$ as adsorbates) may be misleading as it does not match the electrochemically active surface in the supercapacitor.

\section{Acknowledgements}

Financial support to T.A.C. from EU 7FP (Project Electrograph- 266391) and MICINN (project MAT 2011-25198) is gratefully acknowledged. Financial support for graphene oxide development was obtained from the Research Council of Norway, through grant No 73146. The authors thank the Instituto Universitario de Investigación en Nanociencia de Aragón-Universidad de Zaragoza for the HRTEM images.

\section{References}

[1] M. Conte, Supercapacitors technical requirements for new applications, Fuel Cells $10(2010) 806$.

[2] M. Winter, R. J. Brodd, What are batteries, fuel cells and supercapacitors?, Chem Rev. 104 (2004) 4245. 
[3] L. L. Zhang, X. S. Zhao, Carbon-based materials as supercapacitor electrodes, Chem Soc. Rev. 38 (2009) 2520.

[4] M. Inagaki, H. Konno, O. Tanaike, Carbon materials for electrochemical capacitors, J. Power Sources 195 (2010) 7880.

[5] Y. Zhai, Y. Dou, D. Zhao, P. F. Fulvio, R. T. Mayes, S. Dai, Carbon materials for chemical capacitive energy storage, Adv. Mater 23 (2011) 4828.

[6] E. Frackowiak, F. Béguin, Electrochemical storage of energy in carbon nanotubes and nanostructured carbons, Carbon 40 (2002) 1775-1787.

[7] P. J. Hall, M. Mirzaeian, S. I. Fletcher, F. B. Sillars, A. J. R. Rennie, G. O. ShittaBey, G. Wilson, A. Cruden, R. Carter, Energy storage in electrochemical capacitors: Designing functional materials to improve performance, Energy Environ. Sci. 3 (2010) 1238.

[8] J. Biener, M. Stadermann, M. Suss, M. A. Worsley, M. M. Biener, K. A. Rose, T. F. Baumann, Advanced carbon aerogels for energy applications, Energy Environ. Sci. 4 (2011) 656.

[9] H. Nishihara, T. Kyotani, Templated nanocarbons for energy storage, Adv. Mater 24 (2012) 4473.

[10] J. Chmiola, G. Yushin, Y. Gogotsi, C. Portet, P. Simon, P. L. Taberna, Anomalous increase in carbon capacitance at pore sizes less than 1 nanometer, Science 313 (2006) 1760.

[11] Y. Huang, J. Liang, Y. Chen, An overview of the applications of graphene-based materials in supercapacitors, Small 8 (2012) 1805.

[12] Y. B. Tan, J. M. Lee, Graphene for supercapacitor applications, J. Mater. Chem. A $1(2013) 14814$. 
[13] M. D. Stoller, S. J. Park, Y. W. Zhu, J. H. An, R. S. Ruoff, Graphene-based ultracapacitors, Nano Lett. 8 (2008) 3498.

[14] Y. Zhu, S. Murali, W. Cai, X. Li, J. W. Suk, J. R. Potts, R. S. Ruoff, Graphene and graphene oxide: Synthesis, properties, and applications, Adv. Mater. 22 (2010) 3906.

[15] Y. Zhu, S. Murali, M. D. Stoller, K. J. Ganesh, W.Cai, P. J. Ferreira, A. Pirkle, R. M. Wallace, K. A. Cychosz, M. Thommes, D. Su, E. A. Starch, R. S. Ruoff, Carbonbased supercapacitors produced by activation of graphene, Science 332 (2011) 1537.

[16] B. Xu, S. Yue, Z. Sui, X. Zhang, S. Hou, G. Cao, Y. Yang, What is the choice for supercapacitors: graphene or graphene oxide?, Energy Environ. Sci. 4 (2011) 2826.

[17] D. Zhang, X. Zhang, X. Sun, H. Zhang, C. Wang, Y. Ma, High performance supercapacitor electrodes based on deoxygenated graphite oxide by ball milling, Electrochim. Acta 109 (2013) 874.

[18] W. S. Hummers, R. E. Offeman, Preparation of graphitic oxide, J. Am. Chem. Soc. $80(1958) 1339$.

[19] R. Wendelbo, S. Fotedar, Norwegian Patent Application No. 20121709

[20] M. J. McAllister, J. L. Li, D. H. Adamson, H. C. Schniepp, A. A. Abdala, J. Liu, M. Herrera-Alonso, D. L. Milius, R. Car, R. K. Prud'homme, I. A. Aksay, Single sheet functionalized graphene by oxidation and thermal expansion of graphite, Chem. Mater. 19 (2007) 4396.

[21] H. P. Boehm, Graphene-How a laboratory curiosity suddenly became extremely interesting, Angew. Chem. Int. Ed. 49 (2010) 9332.

[22] M. S. Dresselhaus, G. Dresselhaus, R. Saito, A. Jorio, Raman spectroscopy of carbon nanotubes, Phys. Rep. 409 (2005) 47. 
[23] T. A. Centeno, F. Stoeckli, The role of textural characteristics and oxygencontaining surface groups in the supercapacitor performances of activated carbons, Electrochim. Acta 52 (2006) 560-566.

[24] T. A. Centeno, M. Hahn, J. A. Fernández, R. Kötz, F. Stoeckli, Correlation between capacitances of porous carbons in acidic and aprotic EDLC electrolytes, Electrochem. Commun. 9 (2007) 1242.

[25] G. Lota, T. A. Centeno, E. Frackowiak, F. Stoeckli, Improvement of the structural and chemical properties of a commercial activated carbon for its application in electrochemical capacitors, Electrochim. Acta 53 (2008) 2210.

[26] M. Olivares-Marín, J. A. Fernández, M. J. Lázaro, C. Fernández-González, A. Macías-García, V. Gómez-Serrano, F. Stoeckli, T. A. Centeno, Cherry stones as precursor of activated carbons for supercapacitors, Mater. Chem. Phys. 114 (2009) 323.

[27] J. A. Fernández, S. Tennison, O. Kozynchenko, F. Rubiera, F. Stoeckli, T. A. Centeno, Effect of mesoporosity on specific capacitance of carbons, Carbon 47 (2009) 1598.

[28] M. Domingo-García, J. A. Fernández, M. C. Almazán-Almazán, F. J. LópezGarzón, F. Stoeckli, T. A. Centeno, Poly(ethylene terephthalate)-based carbons as electrode material in supercapacitors, J. Power Sources 195 (2010) 3810.

[29] T. A. Centeno, F. Stoeckli, Surface-related capacitance of microporous carbons in aqueous and organic electrolytes, Electrochim. Acta 56 (2011) 7334.

[30] G. Dobele, T. Dizhbite, M. V. Gil, A. Volpert, T. A. Centeno, Production of nanoporous carbons from wood processing wastes and their use in supercapacitors and $\mathrm{CO}_{2}$ capture, Biomass Bioenerg. 46 (2012) 145.

[31] T. A. Centeno, J. A. Fernández, F. Stoeckli, Correlation between heats of immersion and limiting capacitances in porous carbons, Carbon 46 (2008) 1025. 
[32] F. Stoeckli, Characterization of microporous carbons by adsorption and immersion techniques, in J. W. Patrick (Ed.), Porosity in Carbons. Characterization and applications, Arnold, London, 1995, p. 67.

[33] D. Lozano-Castelló, D. Cazorla-Amorós, A. Linares-Solano, Usefulness of $\mathrm{CO}_{2}$ adsorption at $273 \mathrm{~K}$ for the characterization of porous carbons, Carbon 42 (2004) 1233. [34] F. Stoeckli, T. A. Centeno, Optimization of the characterization of porous carbons for supercapacitors, J. Mater. Chem. A 1 (2013) 6865.

[35] M. Toyoda, Y. Tani, Y. Soneda, Exfoliated carbon fibers as an electrode for electric double layer capacitors in a $1 \mathrm{~mol} / \mathrm{dm}^{3} \mathrm{H}_{2} \mathrm{SO}_{4}$ electrolyte, Carbon 42 (2004) 2833.

[36] M. M. Hantel, T. Kaspar, R. Nesper, A. Wokaun, R. Kötz, Partially reduced graphite oxide for supercapacitor electrodes: Effect of graphene layer spacing and huge specific capacitance, Electrochem. Commun. 13 (2011) 90.

[37] S. Mitani, M. Sathish, D. Rangappa, A. Unemoto, T. Tomai, I. Honma, Nanographene derived from carbon nanofiber and its application to electric double-layer capacitors, Electrochim. Acta 68 (2012) 146.

[38] Y. Gogotsi, P. Simon, True performance metrics in electrochemical energy storage, Science 334 (2011) 917. 
Figure 1. TPD profile of the graphite oxide showing blasting at $127^{\circ} \mathrm{C}$

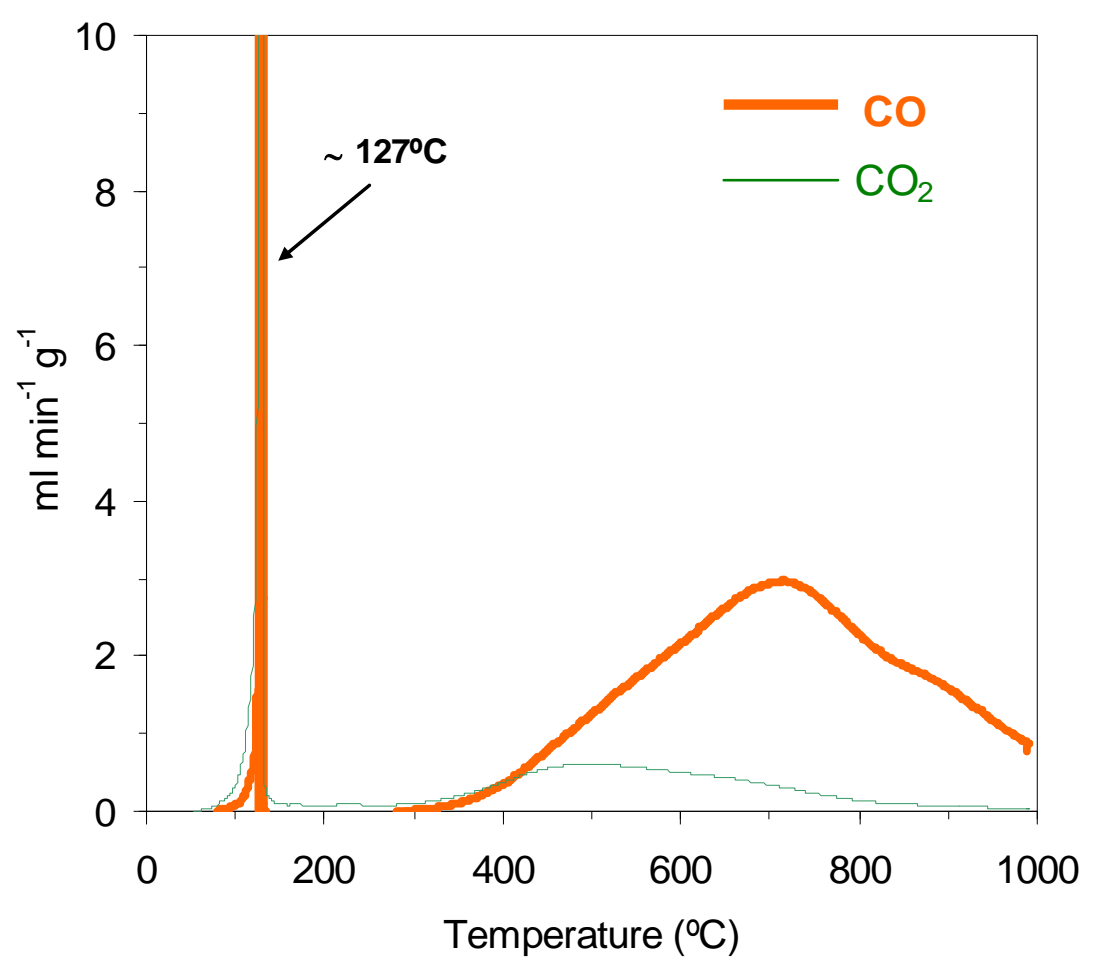


Figure 2. SEM (a) and HRTEM (b) images of the graphite oxide.
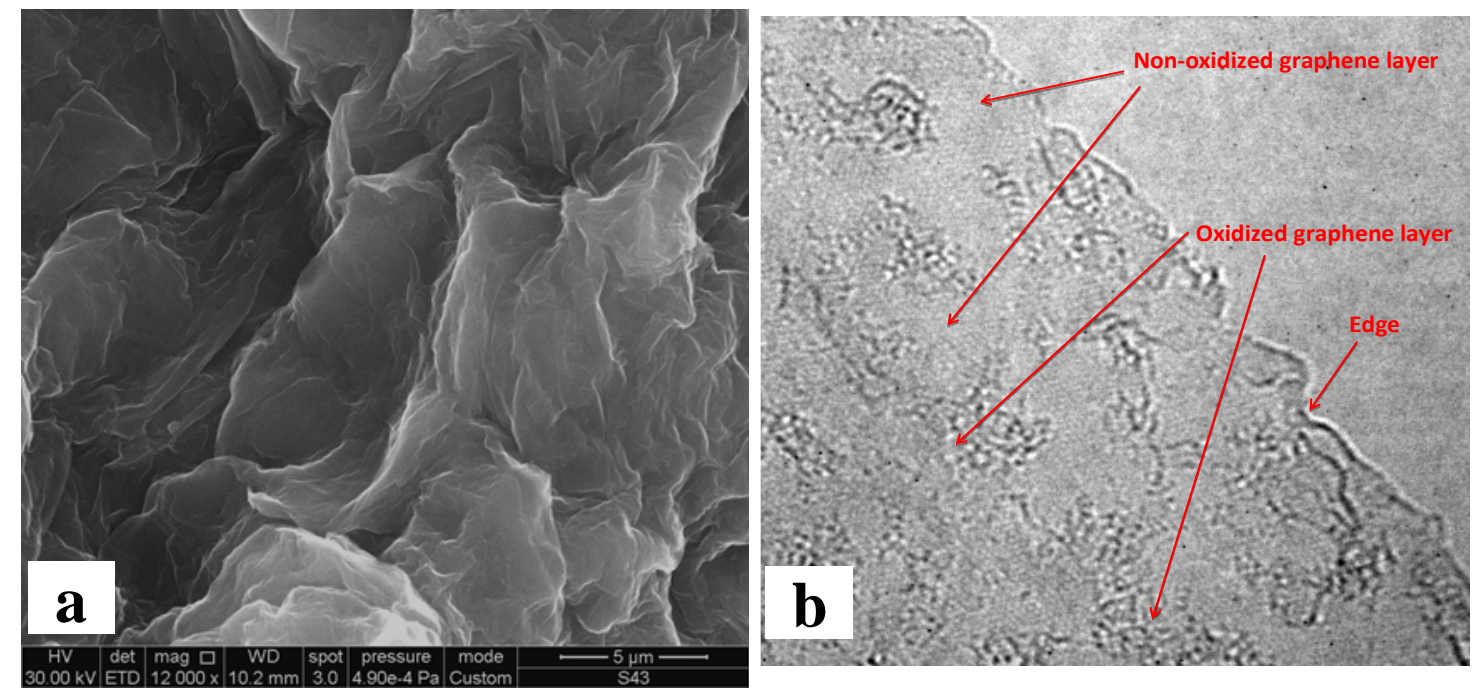
Figure 3. XRD (a) and Raman (b) spectra for the graphite oxide and the raw graphite
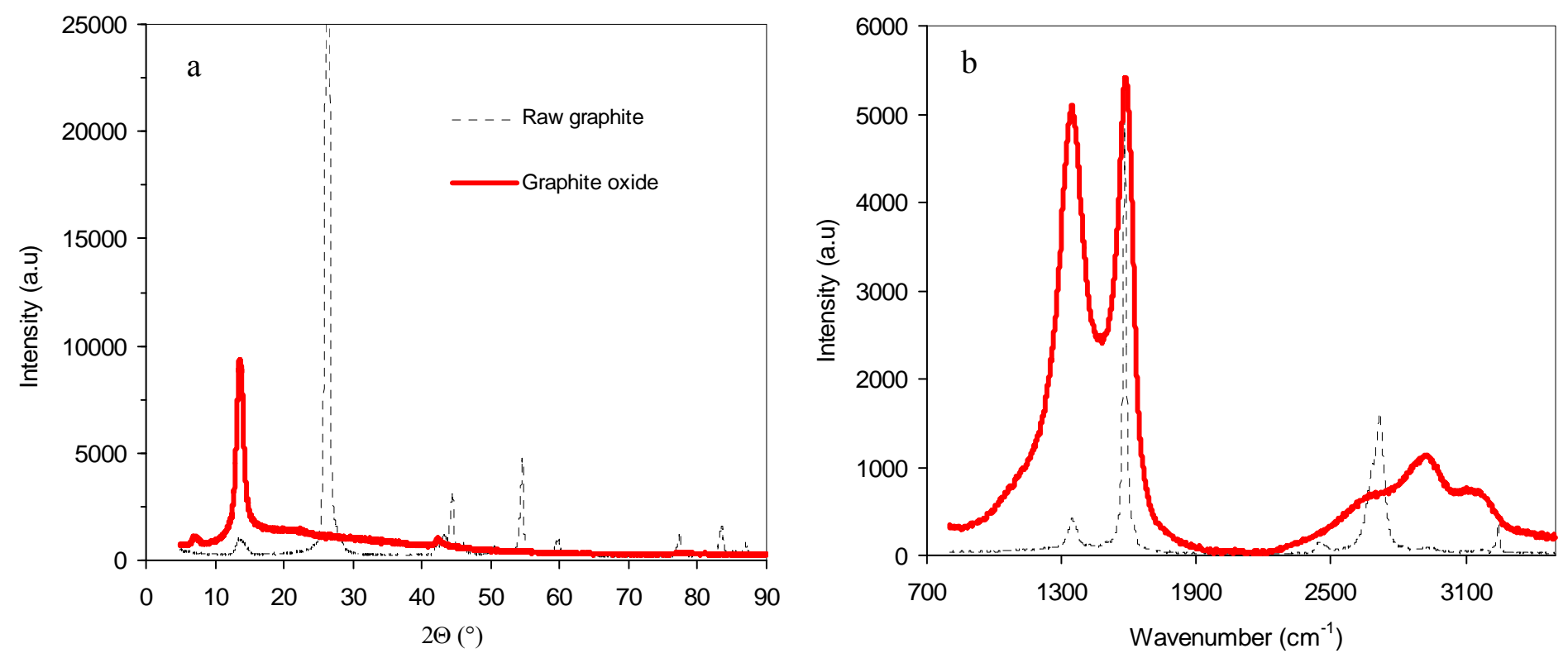
Figure 4. Cyclic voltammograms for the devices with graphite oxide based-electrodes at $1 \mathrm{mV} \mathrm{s}^{-1}$ in $\mathrm{H}_{2} \mathrm{SO}_{4}$
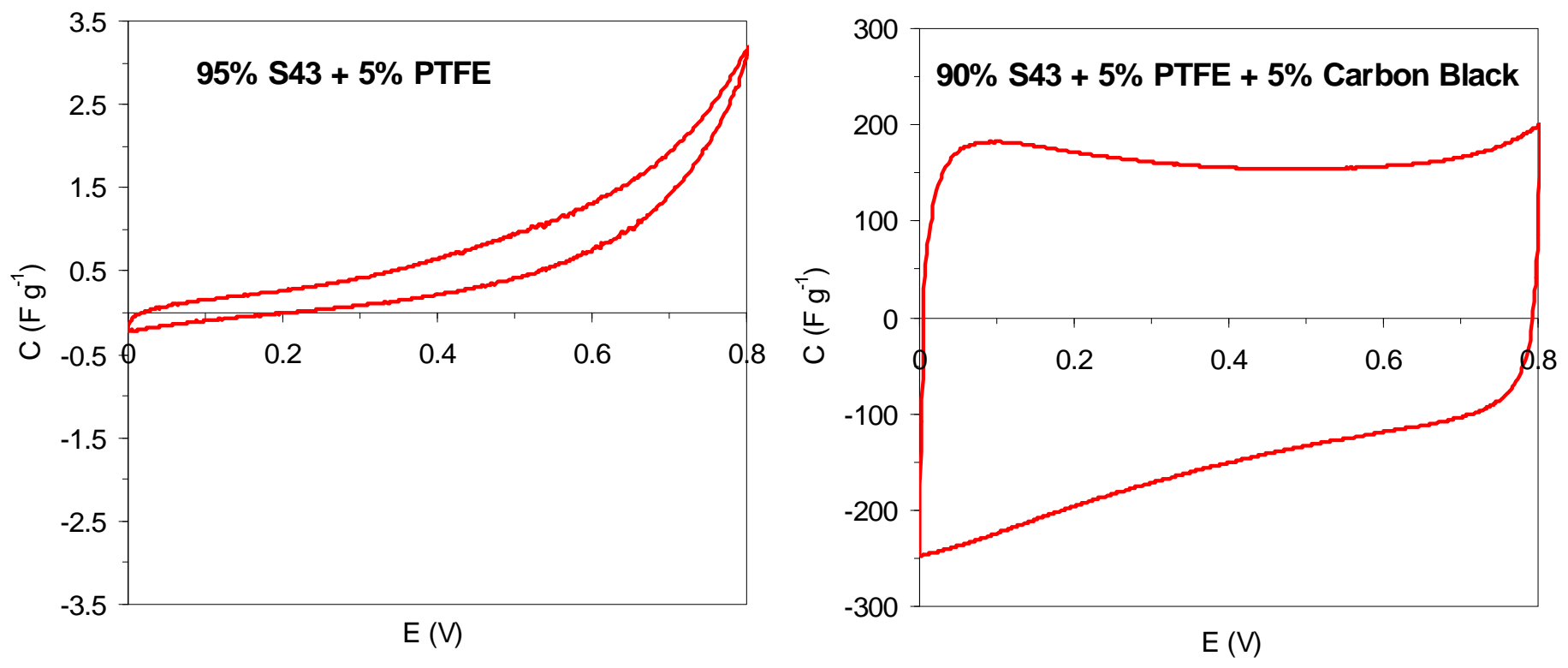
Figure 5. Variation of the specific capacitance $\left(1 \mathrm{~mA} \mathrm{~cm}{ }^{-2}\right)$ in $2 \mathrm{M} \mathrm{H}_{2} \mathrm{SO}_{4}$ and $1 \mathrm{M}$ $\mathrm{TEABF}_{4} / \mathrm{AN}$ with the total surface area for various carbon materials: graphite oxide S43 $(\square)$, graphene nanoplatelets $(\square)$, Picactif SC $(\bullet)$ and different activated carbons (०) [23$31]$.
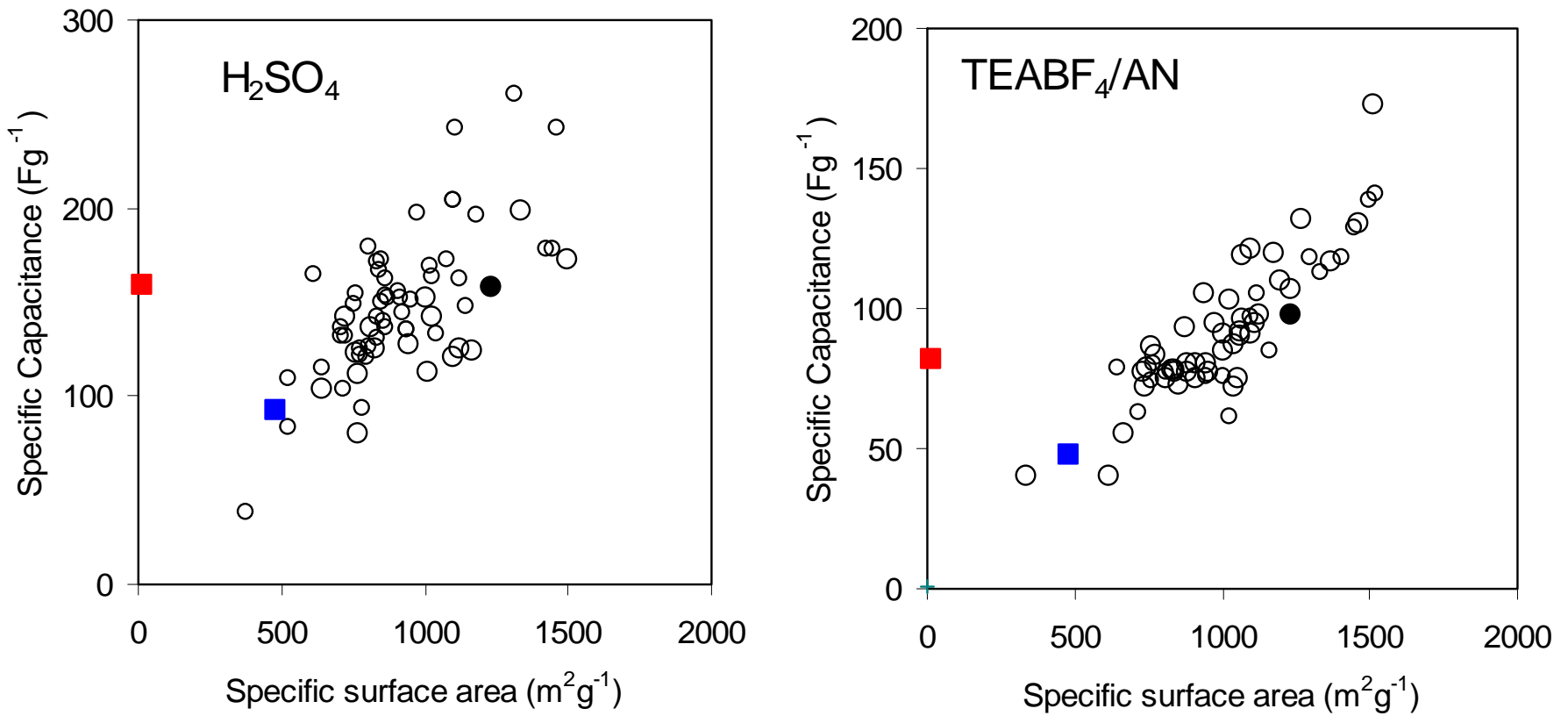
Figure 6. Characteristic curve obtained from $\mathrm{N}_{2}-77 \mathrm{~K}$ and $\mathrm{CO}_{2}-273 \mathrm{~K}$ adsorption on the graphite oxide.

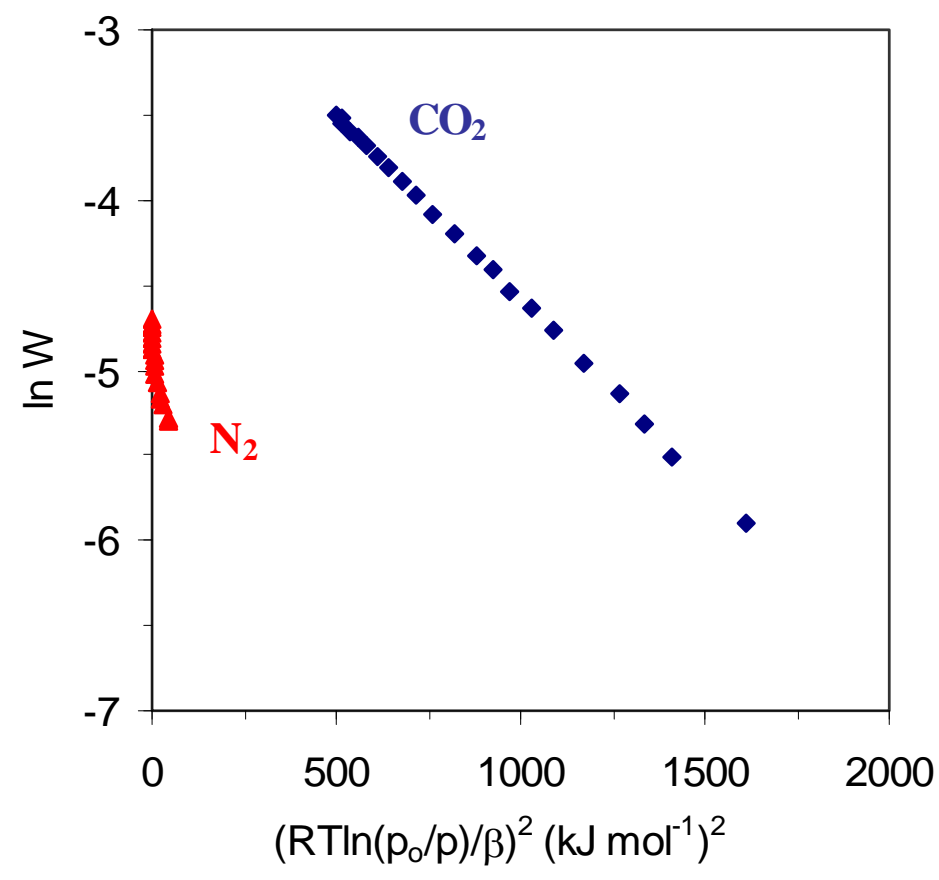


Figure 7. Evolution of the specific capacitance of the graphite oxide S43 (匹), the graphene nanoplatelets $(\square)$ and the activated carbon Picactif SC (०) with the current density in the aqueous and the organic electrolytes.
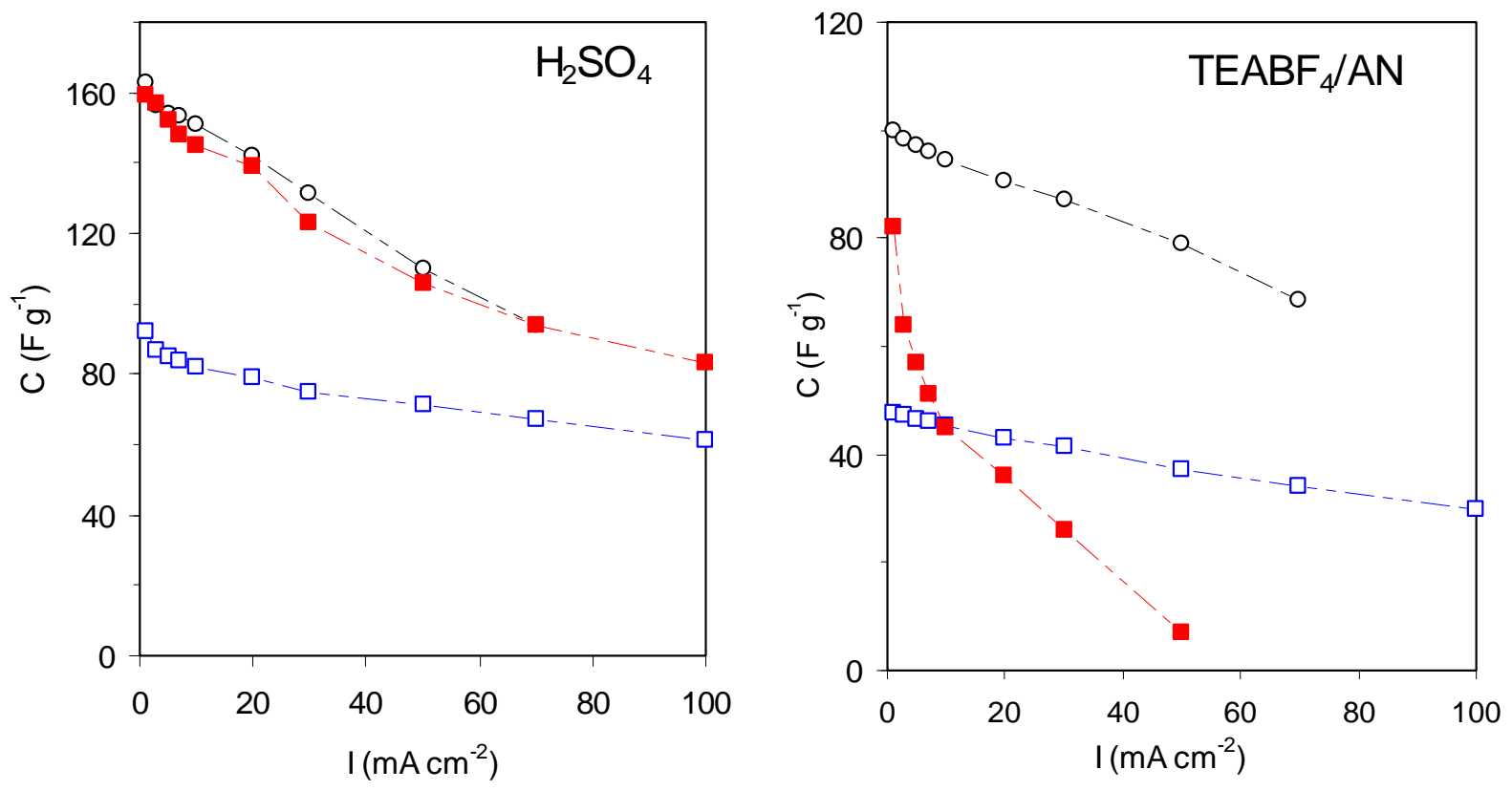
Figure 8. Magnification of the high frequency region of the Nyquist plot and the dependence of the imaginary capacitance (C") as a function of the frequency (inset): graphite oxide S43 ( $\square$ ), graphene nanoplatelets ( $\square$ ) and activated carbon Picactif SC (०).
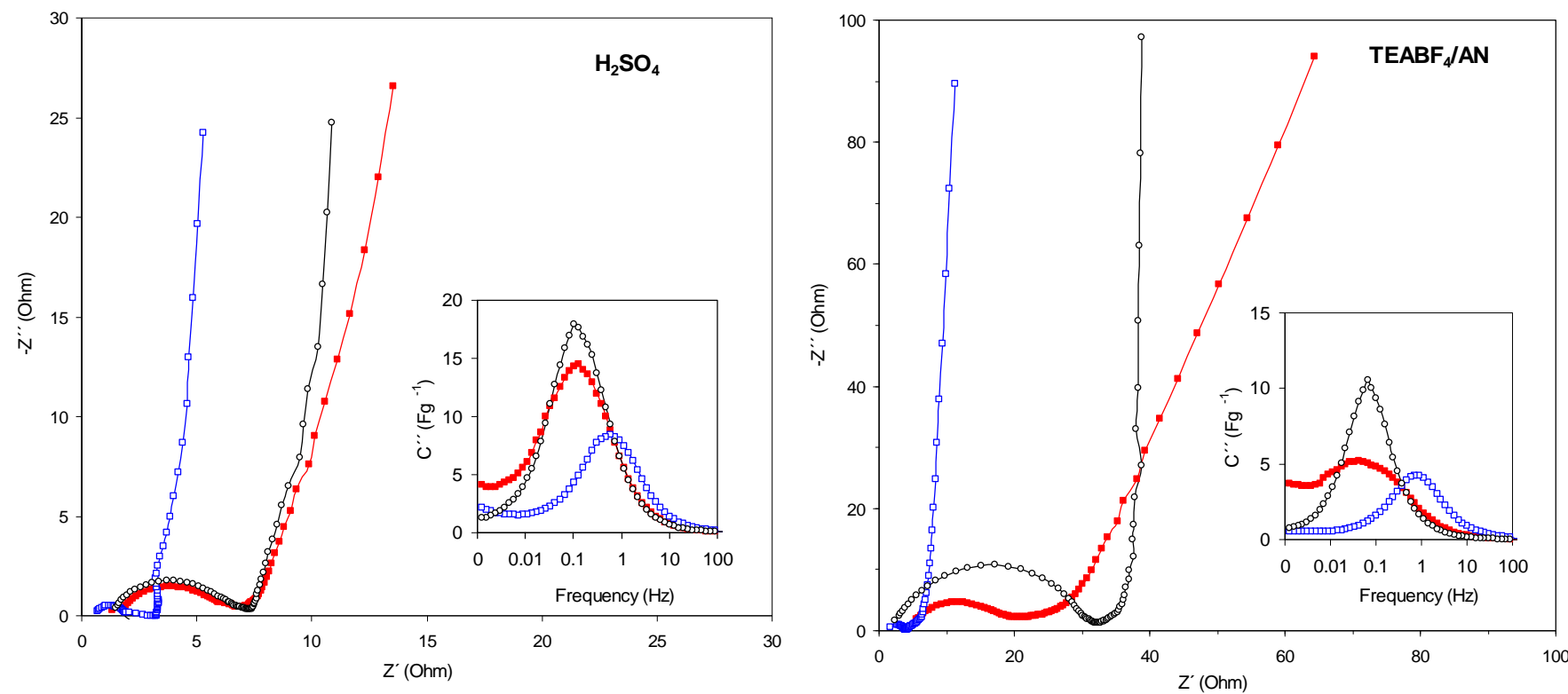
Figure 9. Ragone-type plots showing both average power density and energy density for: S43 $(\square, \square)$, graphene nanoplatelets $(\square, \square)$ and Picactif $(\bullet, \circ)$. Closed symbols for $2 \mathrm{M}$ $\mathrm{H}_{2} \mathrm{SO}_{4}$ aqueous solution. Open symbols for $1 \mathrm{M}$ TEABF $4 / \mathrm{AN}$

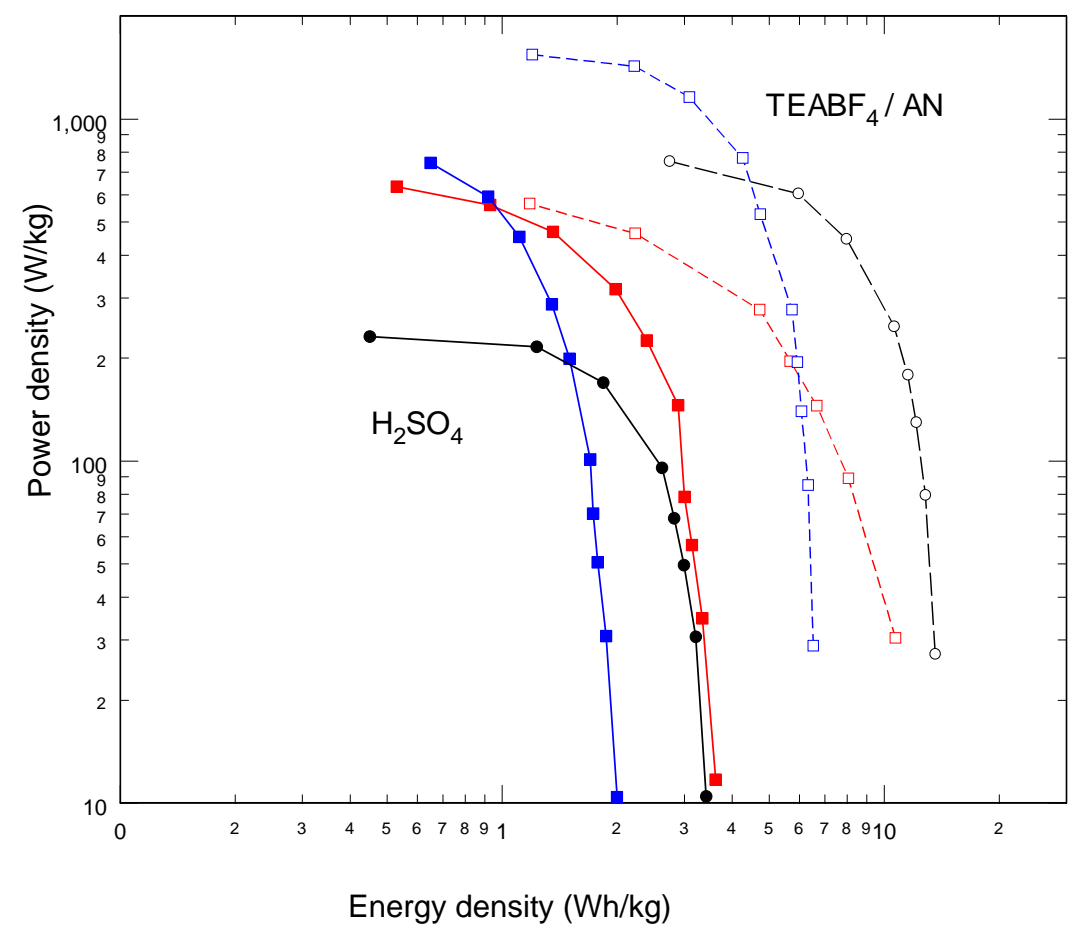




\section{Supporting Information}

Title Graphite oxide: An Interesting Candidate for Aqueous Supercapacitors Belén Lobato, Rune Wendelbo, Violeta Barranco and Teresa A. Centeno*

\section{MATERIALS}

For comparison two carbons available on the market were used:

i) Activated carbon Picactif SC (Pica, USA). It is an essentially mesoporous carbon (pore size $>2 \mathrm{~nm}$ ) although with a significant contribution of supermicropores (1.5-2 $\mathrm{nm})$. Its surface area estimated by BET equation is as high as $2260 \mathrm{~m}^{2} / \mathrm{g}$. This value is misleading as the presence of pores $1.5-2 \mathrm{~nm}$ leads to a $\mathrm{S}_{\mathrm{BET}}$ surface area much higher than the real surface area [1]. The combination of different techniques reports a real surface area of $1231 \mathrm{~m}^{2} / \mathrm{g}$.

ii) Graphene nanoplatelets C-750 (XG Sciences, USA). Its particles typically consist of aggregates of sub-micron platelets that have a particle diameter of less than $2 \mu \mathrm{m}$ and a typical particle thickness of a few nanometers with a surface area estimated by BET equation of around $700 \mathrm{~m}^{2} / \mathrm{g}$. This value is unreliable as this sample presents a high contibution of pores around $1.9 \mathrm{~nm}$. The estimation of the specific surface area of this material by a combination of different techniques reports a real surface area of 479 $\mathrm{m}^{2} / \mathrm{g}$. 


\section{CHARACTERIZATION}

Elemental analysis, TPD (temperature programmed desorption), XRD, Raman spectroscopy, XPS, SEM, and Gas adsorption were used to monitor the chemical and structural changes occurring in the different materials.

\section{- Elemental analysis}

A LECO Tru Spec microanalyzer was used to calculate the $(\mathrm{C}, \mathrm{H}, \mathrm{N})$ composition of the carbons. The oxygen content was directly in a LECO-TF-900 furnace coupled to a LECO-CHNS-932 microanalyzer.

\section{- TPD}

Thermal Programmed Desorption system consisted of an electrical furnace with a Ushape quartz glass reactor connected to a mass spectrometer Omnistar ${ }^{\mathrm{TM}}$ (Pheiffer Vacuum). Initially, the samples were degassed under an Argon flow $\left(50 \mathrm{ml} \mathrm{min}^{-1}\right)$ at room temperature for $1 \mathrm{~h}$. Then they were heated from room temperature at a heating rate of $10^{\circ} \mathrm{C} \min ^{-1}$, up to $1000^{\circ} \mathrm{C}$.

\section{- XPS}

For X-ray photoelectron spectroscopy measurements, a customized SPECS system was employed working under a pressure of $5^{*} 10^{-9} \mathrm{mbar}$ with a $\mathrm{Mg} \mathrm{K} \quad \mathrm{X}$-ray source operated at $150 \mathrm{~W}$.

The XPS high-resolution C1s spectrum was deconvoluted employing GaussianLorentzian (80:20) functions after Shirley background correction in order to identify the functional groups and their respective percentages. The C1s signal was fitted to six components centered at binding energies of $284.6 \mathrm{eV}, 285.5 \mathrm{eV}, 286.6 \mathrm{eV}, 287.7 \mathrm{eV}$, $289.0 \mathrm{eV}, 290.3 \mathrm{eV}$ assigned, respectively, to graphitic or $\mathrm{sp}^{2}$-hybridised carbon, damaged structures or $\mathrm{sp}^{3}$-hybridised carbon, hydroxyl/epoxy/ether groups, carbonyl groups and carboxyl groups and $\pi-\pi^{*}$ shake up (typical for $\mathrm{sp}^{2}$-hydridized carbon). 


\section{- Microscopy}

The morphology of the samples was examined by Scanning Electron Microscopy using a field emission gun scanning electron microscope QUANTAN FEG 650 (FEI) operating at $30 \mathrm{kV}$.
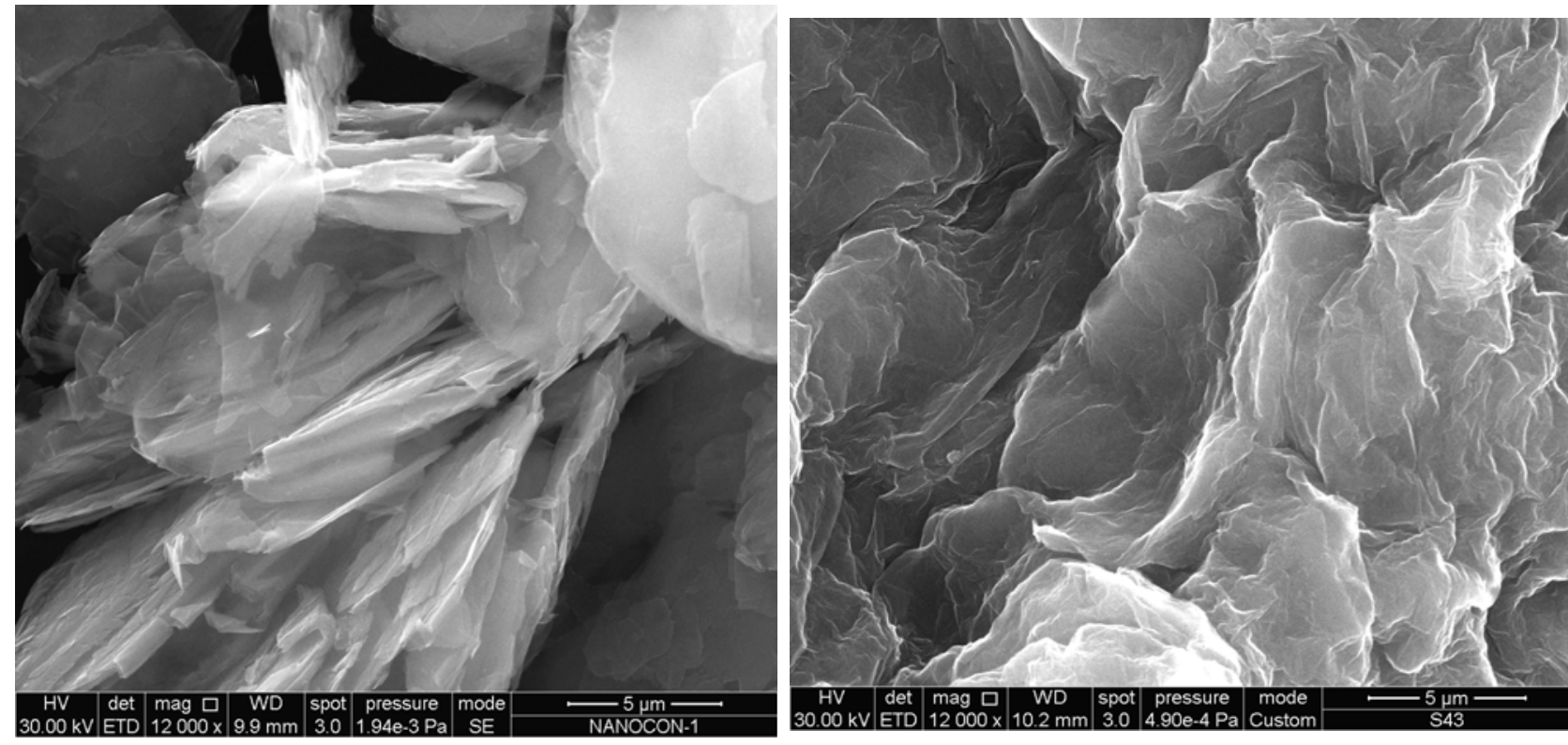

Figure S1. SEM images of the raw graphite (left) and the graphite oxide S43 (right)

The observation by HRTEM shows regions with different oxidation degree

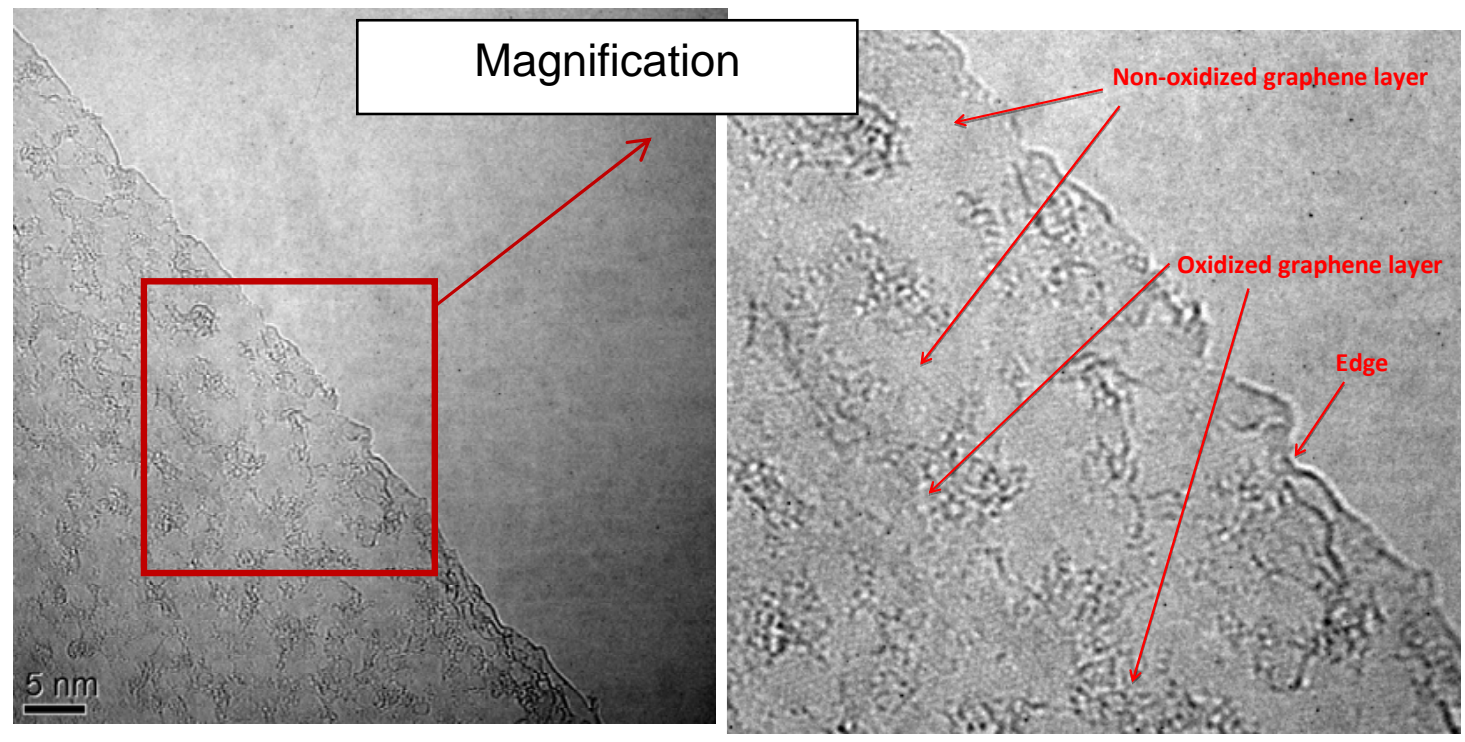

Figure S2. HRTEM images of graphite oxide S43 
- XRD

XRD analysis of powdered samples was performed using a D5000 (Siemens) diffractometer. The radiation frequency employed was the $\mathrm{K} \alpha 1$ line from $\mathrm{Cu}$ $\left(1.5406 \mathrm{~A}^{\circ}\right)$, with a power supply of $40 \mathrm{kV}$ and $40 \mathrm{~mA}$. The reflections were recorded at steps of $0.02^{\circ}$ and intervals of $1 \mathrm{~s}$ per step in the 2 . range of $5-90^{\circ}$.

\section{- Raman}

Raman spectroscopy was performed on a labRam HR UV 800 (Horiba-Jobin YVon) coupled to a confocal microscope BXFM-ILHS (Olympus). The source of radiation was a laser DPSS (CDPS532M) operating at a wavelength of $532 \mathrm{~nm}$ and a power of 24.3 $\mathrm{mW}$. Spectra were recorded from 800 to $3500 \mathrm{~cm}^{-1}$.

\section{- Textural characterization}

The textural features were estimated from the analysis of nitrogen sorption isotherm at 77K by different methods such as BET equation, Dubinin's theory, DFT approach and comparison plot. ${ }^{[1-5]}$

It was complemented with the analysis of the adsorption isotherm of $\mathrm{CO}_{2}$ at $273 \mathrm{~K}$ with the Dubinin-Radushkevich equation.$^{[1-5]}$ This equation describes the volume filling of micropores by vapours over a wide range of relative pressures and temperature.

$$
\mathrm{W}=\mathrm{W}_{\mathrm{o}} \exp \left[-\left(\mathrm{RT} \ln \left(\mathrm{p}_{\mathrm{o}} / \mathrm{p}\right) / \beta \mathrm{E}_{\mathrm{o}}\right)^{2}\right]
$$

where

$-\mathrm{W}_{\mathrm{o}}$ is the limiting volume of the micropores and $\mathrm{W}$ the volume filled at $\left(\mathrm{T} ; \mathrm{p} / \mathrm{p}_{\mathrm{o}}\right)$.

- $E_{o}$ is the so-called characteristic energy of adsorption, which depends on both the solid and the adsorbate.

It has been shown that for adsorptives without specific interactions with the carbon, there exists a scaling factor, called the affinity coefficient $\beta$, relative to benzene taken as 
a reference. For the adsorbates used in this study, $\mathrm{N}_{2}$ and $\mathrm{CO}_{2}, \beta\left(\mathrm{N}_{2}\right)=0.33$, and $\beta\left(\mathrm{CO}_{2}\right)$ $=0.36$.

The representation of $\mathrm{W}$ versus $\left.\ln \mathrm{RT} \ln \left(\mathrm{p}_{\mathrm{o}} / \mathrm{p}\right) / \beta\right)^{2}$ (Characteristic curve) is a straight line whose intersection with the ordinate axis provides the micropore volume $\mathrm{W}_{\mathrm{o}}$ and from the slope the value is obtained the characteristic energy $\left(\mathrm{E}_{\mathrm{o}}\right)$.

The characteristic energy $E_{o}$ is related to the average size of the micropores $L_{o}$ by the equation $\mathrm{L}_{\mathrm{o}}(\mathrm{nm})=10.8 /\left[\mathrm{E}_{\mathrm{o}}(\mathrm{kJ} / \mathrm{mol})-11.4\right]$

For slit-shaped micropores the corresponding surface area $\left(\mathrm{S}_{\mathrm{mi}}\right)$ is determined by the equation $\mathrm{S}_{\mathrm{mi}}\left(\mathrm{m}^{2} / \mathrm{g}\right)=2000 \mathrm{~W}_{\mathrm{o}}\left(\mathrm{cm}^{3} / \mathrm{g}\right) / \mathrm{L}_{\mathrm{o}}(\mathrm{nm})$

\section{- Electrochemical performance}

Electrochemical characterization of carbon electrodes was conducted in two-electrodes Swagelok cell in which glassy microfibre paper (Whatman 934-AH) was used as separator. In a first test, the electrodes were prepared by mixing $95 \mathrm{wt} \%$ of dry S43 flakes with $5 \mathrm{wt} \%$ of polytetrafluoroethylene (PTFE). Due to their poor performance, the carbon black Super-P was further added to the composite (90 wt $\% \mathrm{~S} 43,5 \mathrm{wt} \%$ PTFE, $5 \mathrm{wt} \%$ Super P). Supercapacitor electrodes were processed as cylindrical pellets of $8 \mathrm{~mm}$ diameter and ca. $140 \mu \mathrm{m}$ height.

Cyclic voltammetry $(\mathrm{CV})$ tests at various scan rates $\left(1-50 \mathrm{mV} \mathrm{s}^{-1}\right)$ as well as galvanostatic charge-discharge cycles at different current densities $\left(1-50 \mathrm{~mA} \mathrm{~cm}^{-2}\right)$ were performed between 0 and $0.8 \mathrm{~V}$ in $2 \mathrm{M}$ aqueous $\mathrm{H}_{2} \mathrm{SO}_{4}$ and from 0 to $2 \mathrm{~V}$ in the organic electrolyte $\mathrm{TEABF}_{4}$-acetonitrile. Electrochemical impedance spectroscopy (EIS) measurements were performed by applying a sinusoidal signal of $\pm 15 \mathrm{mV}$ from $210^{-4}$ $\mathrm{Hz}$ to $60 \mathrm{kHz}$ in a PGSTAT 30 (Autolab B.V., Metrohm) potentiostat equipped with a FRA32M module. 

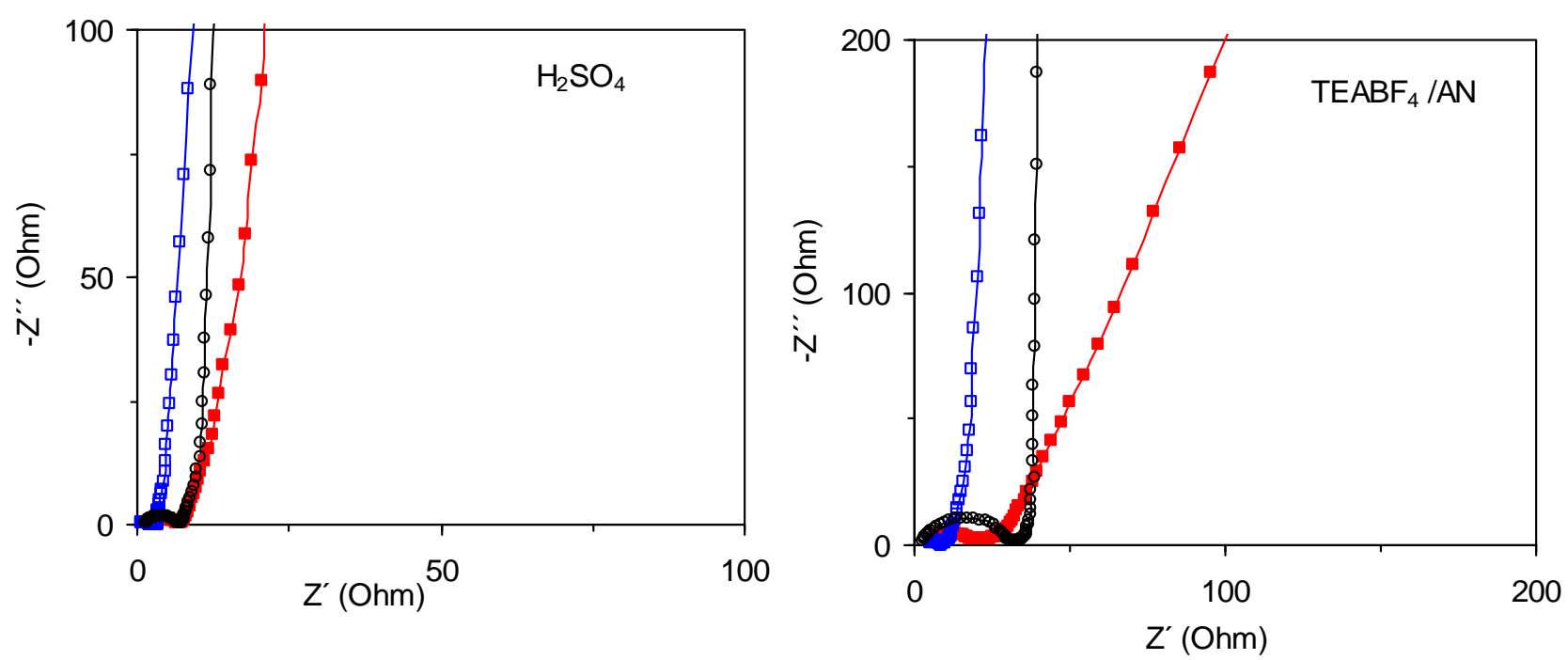

Figure S3. Nyquist plot for the graphite oxide S43 ( $\square)$, the graphene nanoplatelets GNP ( $\square$ ) and the activated carbon Picactif SC (०).

\section{REFERENCES}

[1] F. Stoeckli, T.A. Centeno. J. Mater. Chem. A 2013, 1, 6865-6873.

[2] R.C. Bansal, J.B. Donnet, F. Stoeckli, Active Carbon, Marcel Dekker, New York, 1988, pp. 119

[3] M.M. Dubinin, Carbon 1989, 27, 457-467.

[4] F. Stoeckli, Russ. Chem. Bull. Int. Ed. 2001, 50, 2265-2270.

[5] D. Lozano-Castelló, D. Cazorla-Amorós, A. Linares-Solano. Carbon 2004, 42, $1233-1242$. 